e-ISSN 2580-5118

p-ISSN 2548-1827

\title{
PENERAPAN ALTMAN Z-SCORE DALAM MEMPREDIKSI KEBANGKRUTAN PADA PT BANK MANDIRI (PERSERO) TBK
}

\author{
Eva Malina Simatupang \\ Politeknik Negeri Medan \\ email: evasimatupang14@gmail.com
}

\begin{abstract}
The purpose of this study is to determine and analyze the risk of bankruptcy of goverment PT Bank Mandiri (Persero) Tbk by Altman Z-Score. Population of this study is PT Bank Mandiri (Persero) Tbk financial statements and sample of this study is PT Bank Mandiri (Persero) Tbk financial a statements 2014-2018. Data type used is secondary data and data collection technique is documentation from financial statements published on www.bankmandiri.co.id. Data processing technique used Altman $Z$-Score methode Modification version. Based on the result data processing, obtained results Z-Score at 2014 is 2,04; 2015 is 2,13; 2016 is 1,98; 2017 is 2,10 and 2018 is 2,22. Based on the data analyze it can be concluded PT Bank Mandiri (Persero) Tbk is categorized suffed the threat of Grey Area because the standart score value below 1,81 $<Z<2,99$ and PT Bank Mandiri (Persero) Tbk had the highest risk of bankcruptcy in 2016 with Z-Score in 1,98.
\end{abstract}

Keywords : Prediction, bankruptcy, Altman Z-Score

\section{PENDAHULUAN}

Dalam memprediksi kebangkrutan, terdapat beberapa metode analisis prediksi kebangkrutan, antara lain model yang telah dikembangkan oleh Zmijewski (X-Score), Springate (S-Score), dan Altman (Z-Score). Menurut Hanafi (2003:275), model Altman Z-Score adalah "salah satu model prediksi kebangkrutan dengan tingkat ketepatan prediksi kebangkrutan sebesar 94\% untuk model pertama Altman, dan 95\% untuk model Altman yang telah direvisi dapat memprediksi keadaan perusahaan di Bursa Efek Indonesia”. Sehingga pada penelitian ini dipilihlah metode analisis Altman Z-Score karena mampu memberikan ketepatan prediksi sebesar 95\%. Menurut Subramanyan (2010:288), model prediksi kebangkrutan adalah "Almant Z-Score yang menggunakan teknik Analisis Multiple Discriminant Analysis (MDA)". Alat prediksi ini menggolongkan atau memprediksi kemungkinan bangkrut atau tidak bangkrutnya perusahaan. Almant Z-Score menggunakan lima rasio dalam menganalisis, yaitu modal kerja terhadap total aktiva, laba ditahan terhadap total aktiva, EBIT terhadap total aktiva, nilai pasar saham terhadap nilai buku total hutang, dan penjualan terhadap total aktiva. Model Altman ZScore terbagi atas 3 model, (1) model Altman Z-Score, (2) Model Altman Z-Score Revisi, (3) Model Altman Z-Score Modifikasi. Dalam penelitian ini model Altman Z-Score yang digunakan adalah model Altman Z-Score Modifikasi. Menurut Rudianto (2013:257), rumus Z-Score terakhir ini merupakan rumus yang sangat fleksibel karena bisa digunakan untuk berbagai jenis bidang usaha perusahaan, baik yang go public maupun yang tidak, dan cocok digunakan di negara berkembang seperti Indonesia. Berikut ini merupakan data laporan keuangan PT Bank Mandiri (Persero) Tbk tahun 2014 - 2018. 
Tabel 1.1

Data Aset dan Laba PT Bank Mandiri (Persero) Tbk

tahun $2014-2018$

\begin{tabular}{|c|c|c|}
\hline Tahun & Aset & $\begin{array}{c}\text { Laba Tahun } \\
\text { Berjalan }\end{array}$ \\
\hline 2014 & 855.039 .673 & 20.654 .783 \\
2015 & 910.063 .409 & 21.152 .398 \\
2016 & 1.038 .706 .009 & 14.650 .163 \\
2017 & 1.124 .700 .847 & 21.443 .042 \\
2018 & 1.202 .252 .094 & 25.851 .937 \\
\hline
\end{tabular}

Sumber : Laporan keuangan data diolah, 2019

Berdasarkan tabel diatas dapat dilihat dari tahun 2014 menuju tahun 2015 aset mengalami kenaikan dan laba mengalami kenaikan. Pada tahun 2016, aset mengalami kenaikan tetapi laba mengalami penurunan drastis. Pada tahun 2017, aset mengalami kenaikan dan laba mengalami kenaikan. Pada tahun 2018 aset kembali mengalami kenaikan dan laba mengalami kenaikan. Oleh karena itu, penulis ingin melakukan penelitian terhadap kesehatan bank menggunakan metode Altman Z-Score, karena tahun 2016 bank menunjukkan mengalami penurunan yang sangat drastis. Berdasarkan data-data tersebut, maka peneliti tertarik mengambil judul : "PENERAPAN ALTMAN Z-SCORE DALAM MEMPREDIKSI KEBANGKRUTAN PT BANK MANDIRI (PERSERO) Tbk”.

\section{Rumusan Masalah}

Berdasarkan uraian latar belakang masalah tersebut, maka permasalahan yang akan dihadapi adalah: Bagaimana penerapan Altman Z- Score dalam memprediksi kebangkrutan pada PT Bank Mandiri (Persero) Tbk?

\section{Tujuan Penelitian}

Tujuan penelitian ini untuk mengetahui hasil dari prediksi kebangkrutan PT Bank Mandiri (Persero) Tbk pada periode 2014 - 2018 menggunakan metode Altman Z-Score.

\section{TINJAUAN PUSTAKA}

\section{Kebangkrutan}

Menurut Toto (2011:332), kebangkrutan (bankcruptcy) merupakan kondisi dimana perusahaan tidak mampu lagi untuk melunasi kewajibannya. Kondisi ini biasanya tidak muncul begitu saja di perusahaan, ada indikasi awal dari perusahaan tersebut yang biasanya dapat dikenali lebih dini kalau laporan keuangan dianalisis secara lebih cermat dengan suatu cara tertentu. Rasio keuangan dapat digunakan sebagai indikasi adanya kebangkrutan di perusahaan.

\section{Model Altman Z-Score Modifikasi}

Menurut Rudianto (2013:257), setelah melakukan penelitian dengan objek berbagai perusahaan manufaktur dan menghasilkan 2 (dua) rumus, Altman tidak berhenti. Altman melakukan penelitian lagi mengenai potensi kebangkrutan perusahaan-perusahaan selain perusahaan manufaktur, baik yang go public maupun yang tidak. Rumus Z-Score terakhir merupakan rumus yang sangat fleksibel karena bisa digunakan untuk berbagai jenis bidang usaha perusahaan, baik yang go public maupun tidak, dan cocok digunakan dinegara berkembang seperti Indonesia. 

ini adalah :

Dalam definisi operasional ini, variabel yang akan diamati dalam penyusunan penelitian

a. Rasio Modal Kerja Terhadap Total Aktiva $\left(\mathrm{X}_{1}\right)$

$$
\text { Rasio Modal Kerja Terhadap Total Aktiva }=\frac{\text { Modal kerja }}{\text { Total Aktiva }}
$$

b. Rasio Laba Ditahan Terhadap Total Aktiva $\left(\mathrm{X}_{2}\right)$

Rasio Laba Ditahan Terhadap Total Aktiva $=\frac{\text { Laba Ditahan }}{\text { Total Aktiva }}$

c. Rasio Laba Sebelum Bunga Dan Pajak Terhadap Total Aktiva $\left(\mathrm{X}_{3}\right)$

$$
\text { Rasio EBIT Terhadap Total Aktiva }=\frac{\text { Laba Sebelum Bunga dan Pajak }}{\text { Total Aktiva }}
$$

d. Rasio Nilai Buku Ekuitas Terhadap Nilai Buku Utang $\left(\mathrm{X}_{4}\right)$

$$
\text { Nilai Buku Ekuitas Terhadap Total Liabilitas }=\frac{\text { Nilai Buku Ekuitas }}{\text { Total Liabilitas }}
$$

Adapun nilai cut off yang digunakan adalah:

$$
\begin{array}{ll}
\mathrm{Z}<1,1 & : \text { Bangkrut } \\
1,1<\mathrm{Z}<2,6 & \text { : Grey area (daerah abu-abu) } \\
\mathrm{Z}>2,6 & \text { : Tidak bangkrut }
\end{array}
$$

Keterangan :

$\mathrm{X}_{1}=$ Modal kerja terhadap total aktiva

$\mathrm{X}_{2}=$ Laba ditahan terhadap total aktiva

$\mathrm{X}_{3}=$ Laba sebelum bunga dan pajak terhadap total aktiva

$\mathrm{X}_{4}=$ Nilai buku ekuitas terhadap total liabilitas

\section{METODE}

\section{Populasi dan sampel}

Menurut Sugiyono (2012:80), populasi adalah wilayah generalisasi yang terdiri atas: objek yang mempunyai kualitas dan karakteristik tertentu yang ditetapkan oleh peneliti untuk dipelajari dan kemudian ditarik kesimpulannya. Adapun yang menjadi populasi dalam penelitian ini adalah laporan keuangan PT Bank Mandiri (Persero) Tbk.

Sampel adalah bagian dari elemen-elemen populasi yang terpilih (Sanusi, 2011:87). Metode pengambilan sampel yang digunakan adalah Purposive sampling. Purposive sampling yaitu cara pengambilan sampel yang didasarkan pada pertimbangan yang diberikan oleh sekelompok pakar atau expert (Sanusi,2011:95). Sampel dalam penelitian ini adalah laporan keuangan pada PT Bank Mandiri (Persero) Tbk tahun 2014- 2018 .

\section{Jenis Data}

Jenis data yang digunakan adalah data sekunder. Menurut Sugiyono (2012:225), data sekunder adalah sumber yang tidak langsung memberikan data kepada pengumpul data, misalnya lewat orang lain atau lewat dokumen. Data yang digunakan adalah laporan keuangan PT Bank Mandiri (Persero) Tbk. 
Teknik pengolahan data

$$
\mathrm{Z}=6,56\left(\mathrm{X}_{1}\right)+3,26\left(\mathrm{X}_{2}\right)+6,72\left(\mathrm{X}_{3}\right)+1,05\left(\mathrm{X}_{4}\right)
$$

Keterangan :

$\mathrm{X}_{1}=$ Modal kerja terhadap total aktiva

$\mathrm{X}_{2}=$ Laba ditahan terhadap total aktiva

$\mathrm{X}_{3}=$ Laba sebelum bunga dan pajak terhadap total aktiva

$\mathrm{X}_{4}=$ Nilai buku ekuitas terhadap total liabilitas

Adapun nilai cut off yang digunakan adalah:
$\mathrm{Z}<1,1$
: Bangkrut
$1,1<\mathrm{Z}<2,6$ : Grey area (daerah abu-abu)
$\mathrm{Z}>2,6 \quad$ : Tidak bangkrut

\section{HASIL DAN PEMBAHASAN}

Berikut ini perhitungan dan analisis rasio keempat variabel berdasarkan laporan keuangan publikasi Bank Mandiri (Persero) Tbk tahun 2014-2018 dalam jutaan rupiah.

a. Modal Kerja Terhadap Total Asets $\left(\mathbf{X}_{1}\right)$

Modal Kerja $=($ aktiva lancar - hutang lancar $)$

$$
\text { Rasio Modal Kerja Terhadap Total Aset }=\frac{\text { Modal Kerja }}{\text { Total Aset }}
$$

Tabel 4.2

Perhitungan Modal Kerja (Aktiva Lancar-Hutang Lancar) PT. Bank Mandiri (Persero) Tbk Periode 2014 s.d. 2018

\begin{tabular}{|l|c|c|c|c|c|}
\hline \multirow{2}{*}{$\begin{array}{l}\text { Pos- } \\
\text { Pos }\end{array}$} & \multicolumn{5}{|c|}{ Tahun } \\
\cline { 2 - 6 } & 2014 & 2015 & 2016 & 2017 & 2018 \\
\hline $\begin{array}{l}\text { Aset } \\
\text { Lancar }\end{array}$ & 829.037 .716 & 882.259 .280 & 983.539 .884 & 1.065 .102 .090 & 1.137 .389 .390 \\
\hline $\begin{array}{l}\text { Utang } \\
\text { Lancar }\end{array}$ & 646.826 .456 & 678.053 .672 & 765.452 .725 & 822.982 .102 & 865.459 .839 \\
\hline $\begin{array}{l}\text { Modal } \\
\text { Kerja }\end{array}$ & $\mathbf{1 8 2 . 2 1 1 . 2 6 0}$ & $\mathbf{2 0 4 . 2 0 5 . 6 0 8}$ & $\mathbf{2 1 8 . 0 8 7 . 1 5 9}$ & $\mathbf{2 4 2 . 1 1 9 . 9 8 8}$ & $\mathbf{2 7 1 . 9 2 9 . 5 5 1}$ \\
\hline
\end{tabular}


Tabel 4.3

Perhitungan Rasio $\mathrm{X}_{1}$ (Modal Kerja/Total Aset) pada PT. Bank Mandiri (Persero) Tbk Periode 2014 s.d. 2018

(Dalam Jutaan Rupiah)

\begin{tabular}{|c|c|c|c|c|c|c|}
\hline \multirow{2}{*}{ No } & Nama Bank & \multicolumn{5}{|c|}{ Tahun } \\
\cline { 3 - 7 } & 2014 & 2015 & 2016 & 2017 & 2018 \\
\hline 1 & $\begin{array}{l}\text { PT Bank Mandiri } \\
\text { (Persero) Tbk }\end{array}$ & 0,213103 & 0,224386 & 0,209960 & 0,215275 & 0,226183 \\
\hline
\end{tabular}

Sumber : Data Diolah, 2019

a. Laba Ditahan Terhadap Total Aset $\left(\mathbf{X}_{2}\right)$

Rasio Laba Ditahan Terhadap Total Aset $=\frac{\text { Laba Ditahan }}{\text { Total Aset }}$

Tabel 4.4

Perhitungan Rasio $\mathrm{X}_{2}$ (Laba Ditahan Terhadap Total Aset) Pada PT Bank Mandiri (Persero) Tbk 2014 s.d. 2018

(Dalam Jutaan Rupiah)

\begin{tabular}{|c|r|r|r|}
\hline Tahun & Laba Ditahan & Total Aset & $\begin{array}{c}\text { Laba Ditahan } \\
\text { Terhadap Total } \\
\text { Aset }\end{array}$ \\
\hline 2014 & 74.042 .745 & 855.039 .673 & 0,086596 \\
\hline 2015 & 89.224 .718 & 910.063 .409 & 0,098042 \\
\hline 2016 & 96.930 .793 & 1.038 .706 .009 & 0,093319 \\
\hline 2017 & 111.357 .522 & 1.124 .700 .847 & 0,099011 \\
\hline 2018 & 127.084 .686 & 1.202 .252 .094 & 0,105706 \\
\hline
\end{tabular}

Sumber : Data Diolah, 2019

b. Laba Sebelum Bunga Dan Pajak Terhadap Total Aset $\left(X_{3}\right)$

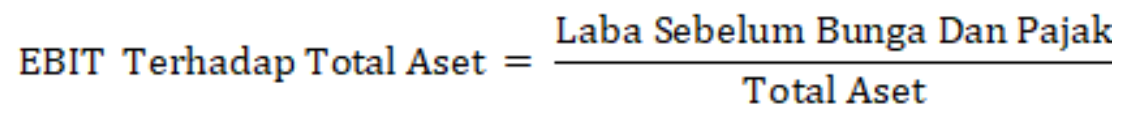


Tabel 4.7

Perhitungan Rasio $\mathbf{X}_{3}$ (Laba Sebelum Bunga Dan Pajak Terhadap Total Asset) PT. Bank Mandiri (Persero) Tbk Periode 2014 s.d. 2018 (Dalam Jutaan Rupiah)

\begin{tabular}{|c|r|r|r|}
\hline Tahun & $\begin{array}{c}\text { Laba Sebelum } \\
\text { Bunga Dan Pajak }\end{array}$ & Total Aset & $\begin{array}{c}\text { Laba Sebelum } \\
\text { Bunga Dan Pajak } \\
\text { Terhadap Total } \\
\text { Aset }\end{array}$ \\
\hline 2014 & 26.008 .015 & 855.039 .673 & 0,030417 \\
\hline 2015 & 26.369 .430 & 910.063 .409 & 0,028975 \\
\hline 2016 & 18.572 .965 & 1.038 .706 .009 & 0,017881 \\
\hline 2017 & 27.156 .863 & 1.124 .700 .847 & 0,024146 \\
\hline 2018 & 33.943 .369 & 1.202 .252 .094 & 0,028233 \\
\hline
\end{tabular}

Sumber : Data Diolah, 2019

c. Nilai Buku Ekuitas Terhadap Nilai Buku Utang $\left(\mathbf{X}_{4}\right)$

Rasio Buku Ekuitas Terhadap Nilai Buku Utang $=\frac{\text { Buku Ekuitas }}{\text { Nilai Buku Utang }}$

Tabel 4.8

Perhitungan Rasio $\mathrm{X}_{4}$ (Nilai Buku Ekuitas Terhadap Nilai Buku Utang) Pada PT. Bank Mandiri (Persero) Tbk Periode 2014 s.d. 2018

(Dalam Jutaan Rupiah)

\begin{tabular}{|c|c|r|r|}
\hline Tahun & $\begin{array}{c}\text { Nilai Buku } \\
\text { Ekuitas }\end{array}$ & $\begin{array}{c}\text { Nilai Buku } \\
\text { Utang }\end{array}$ & $\begin{array}{c}\text { Nilai Buku Ekuitas } \\
\text { Terhadap Nilai Buku }\end{array}$ \\
\hline 2014 & 104.844 .562 & 697.019 .624 & 0,150418 \\
\hline 2015 & 119.491 .841 & 736.198 .705 & 0,162309 \\
\hline 2016 & 153.369 .723 & 824.559 .898 & 0,186002 \\
\hline 2017 & 170.006 .132 & 888.026 .817 & 0,191443 \\
\hline 2018 & 184.960 .305 & 941.953 .100 & 0,196358 \\
\hline
\end{tabular}

Sumber :Data Diolah, 2019 
Hasil Perhitungan Altman Z-Score Modifikasi Pada PT Bank Mandiri (Persero) Tbk periode 2014 s.d. 2018

Model persamaan Altman Z-Score yang digunakan untuk memprediksi kebangkrutan pada Pada PT Bank Mandiri:

$$
Z^{\prime}=6,56 X_{1}+3,26 X_{2}+6,72 X_{3}+1,05 X_{4}
$$

Keterangan :

$\mathrm{X}_{1}=$ Modal kerja terhadap total aset

$\mathrm{X}_{2}=$ Laba ditahan terhadap aset

$\mathrm{X}_{3}=$ Laba sebelum bunga dan pajak terhadap total aset

$\mathrm{X}_{4}=$ Nilai buku ekuitas terhadap nilai buku utang

Adapun nilai cut off yang digunakan adalah:

$\mathrm{Z}<1,1 \quad$ : Bangkrut

$1,1<\mathrm{Z}<2,6 \quad$ : Grey Area $(\mathrm{abu}-\mathrm{abu})$

$Z>2,6$ : Tidak Bangkrut (sehat)

Hasil analisis prediksi kebangkrutan dengan metode Altman Z-Score yang dimodifikasi, dapat dilihat dari tabel dibawah ini :

Tabel 4.9

Hasil Z - Score Pada PT Bank Mandiri (Persero) Tbk

Periode 2014 s.d. 2018

\begin{tabular}{|c|c|c|c|c|c|c|}
\hline Tahun & $\mathrm{X}_{1}$ & $\mathrm{X}_{2}$ & $\mathrm{X}_{3}$ & $\mathrm{X}_{4}$ & Z-Score & Hasil Analisis \\
\hline 2014 & 1,397956 & 0,282303 & 0,204402 & 0,157940 & 2,04 & $\begin{array}{c}\text { Grey area } \\
\text { (daerah abu- } \\
\text { abu) }\end{array}$ \\
\hline 2015 & 1,471972 & 0,319617 & 0,194712 & 0,170424 & 2,16 & $\begin{array}{l}\text { Grey Area } \\
\text { (daerah abu- } \\
\text { abu) }\end{array}$ \\
\hline 2016 & 1,377338 & 0,282303 & 0,120160 & 0,195302 & 1,98 & $\begin{array}{c}\text { Grey Area } \\
\text { (daerah abu- } \\
\text { abu) }\end{array}$ \\
\hline 2017 & 1,412204 & 0,322776 & 0,162261 & 0,201015 & 2,10 & $\begin{array}{c}\text { Grey area } \\
\text { (daerah abu- } \\
\text { abu) }\end{array}$ \\
\hline 2018 & 1,483760 & 0,344602 & 0,189726 & 0,206176 & 2,22 & $\begin{array}{c}\text { Grey area } \\
\text { (daerah abu- } \\
\text { abu) }\end{array}$ \\
\hline \multicolumn{5}{|c|}{ Rata-rata } & 2,1 & $\begin{array}{c}\text { Grey area } \\
\text { (daerah abu- } \\
\text { abu) }\end{array}$ \\
\hline
\end{tabular}

Sumber : Data Diolah, 2019 
Berdasarkan tabel 4.7 dari hasil perhitungan berdasarkan metode Altman Z-Score Modifikasi dari periode 2014 - 2018 menunjukkan bahwa PT Bank Mandiri berada dalam keadaan Grey Area, yaitu keadaan dimana perusahaan tidak dapat ditentukan mengalami kepailitan atau tidak, sebab nilai $Z$-Score rata-ratanya senilai 2,1 atau $1,1<Z<2,6$.

Hasil menunjukkan bahwa nilai Z-Score tertinggi pada PT Bank Mandiri periode 2014 - 2018 dapat dilihat dari grafik dibawah ini:

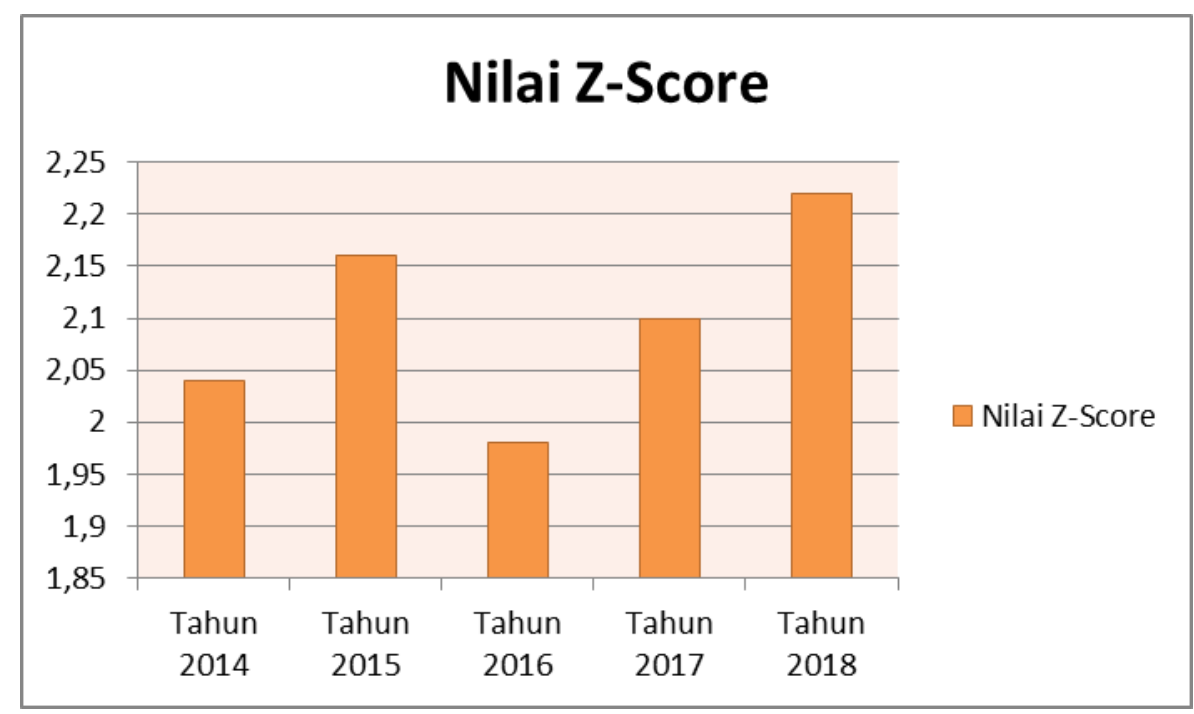

Sumber : Data, 2019

\section{Gambar 4.1}

Nilai Z-Score tertinggi pada PT. Bank Mandiri periode 2014 - 2018

Dari hasil yang diperoleh dapat diketahui bahwa besarnya prediksi financial distress ini dipengaruhi oleh besar kecilnya rasio keuangan perusahaan dan skala Z-Score Altman. Jika semua rasio keuangan bernilai positif maka perusahaan diprediksi dalam kondisi sehat.

Apabila ditinjau dari tingginya tingkat profitabilitas sangat mempengaruhi kondisi perusahaan karena profit merupakan modal bagi perusahaan perbankan untuk melebarkaan usahanya. Dengan tingginya profit tersebut dapat digunakan untuk membiayai beban operasi dan membagikan keuntungan pada pemegang saham. Jika profit menurun atau bahkan sampai merugi maka akan mengganggu keuangan perusahaan perbankan.

Rendahnya profitabilitas dapat menjadikan perusahaan perbankan mengalami gejala pertama kebangkrutan yaitu financial distress karena akan berdampak langsung terhadap penurunan aktiva lancar perusahaan, terhambatnya pelunasan kewajiban dan lain-lain. Selain itu, faktor ekonomi global mempunyai pengaruh sangat tinggi terhadap operasi perusahaan untuk mendapatkan profit, tentu saja hal ini menjadi pengamatan dan pertimbangan bagi para investor untuk menanamkan sahamnya pada perusahaan perbankan dengan melihat rasio keuangan perusahaan dan memilih perusahaan perbankan yang lain yang memiliki perputaran profit yang lebih tinggi dan keuangan yang stabil. Sehingga semakin tinggi rasio profitabiltas suatu perusahaan akan berpengaruh terhadap tingginya nilai Z-Score. Hal ini dilihat dengan tingginya nilai $\mathrm{X}_{3}$ (Laba Sebelum Bunga Dan Pajak Terhadap Total Aset) pada tahun 2018 dan nilai paling rendah di tahun 2016.

Sama halnya dengan rasio likuiditas, aset lancar bernilai kecil juga mempengaruhi Rasio $\mathrm{X}_{1}$ (Modal Kerja/Total Aset) pada Altman Z-Score. Modal kerja bersih yang menurun kemungkinan besar akan menghadapi masalah dalam menutupi kewajiban jangka pendeknya karena tidak tersedianya aktiva lancar yang cukup untuk menutupi kewajiban tersebut. Sebaliknya, perusahaan dengan modal kerja bersih yang meningkat jarang sekali menghadapi kesulitan dalam melunasi kewajibannya. Hal ini terbukti pada tahun 2016 yang memiliki nilai $Z$ Score paling kecil dari pada tahun berikutnya. 
Dari hasil analisis penerapan prediksi kebangkrutan yang dilakukan PT Mandiri (Persero) Tbk tahun 2014 menyatakan bahwa nilai Z-Score sebesar 2,04. Berdasarkan kriteria ZScore $>2,99$ dikategorikan bahwa perusahaan yang berada dalam zona abu-abu, nilai Z-Score kemungkinan beresiko bangkrut mungkin terjadi bagi PT Mandiri (Persero) Tbk.

Hasil analisis Z-Score Altman untuk kinerja keuangan perusahaan PT Mandiri (Persero) Tbk Pada tahun 2015 diperoleh nilai sebesar 2,16. Berdasarkan kriteria Z-Score > 2,99 dikategorikan tersebut perusahaaan mengalami kenaikan hasil dari analisis tahun sebelumnya tetapi masih mungkin mengalami kebangkrutan karena perusahaan yang berada dalam zona abu-abu, yang menyatakan bahwa kondisi keuangan PT Mandiri (Persero) Tbk ini kurang efektif.

Hasil dari perhitungan dengan menggunakan metode Altman Z-Score pada tahun 2016 terdapat bahwa perusahaan dikatakan dalam zona abu-abu dengan menggabungkan empat rasio keuangan dengan menggunakan rumus Z-Score. Dari hasil analisis prediksi kebangkrutan yang dilakukan PT Mandiri (Persero) Tbk Tahun 2016 menyatakan bahwa perusahaan mengalami penurunan yang paling besar dari tahun-tahun sebelumnya dengan nilai Z-Score sebesar 1,98. Berdasarkan kriteria Z-Score > 2,99 dikategorikan bahwa perusahaan yang berada dalam zona abu-abu, nilai Z-Score mengalami penurunan yang besar yang berarti modal kerja juga ikut mengalami penurunan dan kemungkinan beresiko bangkrut mungkin saja lebih besar terjadi dari tahun- tahun sebelumnya.

Hasil analisis metode Altman Z-Score untuk kinerja keuangan PT Mandiri (Persero) Tbk pada tahun 2017 diperoleh nilai sebesar 2,10. Berdasarkan kriteria Z-Score> 2,99 dikategorikan perusahaaan mengalami kenaikan hasil dari analisis tahun sebelumnya tetapi masih mungkin mengalami kebangkrutan. Hal ini menyatakan bahwa kondisi keuangan PT Mandiri (Persero) Tbk mengalami perbaikan yang berarti rasio keuangan yang menggunakan rumus Z-Score mengalami kenaikan yang baik, namun perusahaan masih memiliki kemungkinan untuk mengalami kebangkrutan.

Pada tahun 2018 hasil dari analisis Z-Score Perusahaan ini mengalami Peningkatan kembali. tetapi masih mungkin mengalami kebangkrutan, hal ini menyatakan bahwa kondisi keuangan PT Mandiri (Persero) Tbk mengalami perbaikan yang berarti rasio keuangan yang menggunakan rumus Z-Score mengalami kenaikan yang lagi, namun perusahaan masih memiliki kemungkinan untuk mengalami kebangkrutan. Karena tahun 2018 masih berada pada zona abu-abu. Nilai Z-Score tahun 2018 sebesar 2,22 yang berarti nilai Z- Score paling tinggi dari tahun- tahun sebelumnya .

Berdasarkan grafik hasil perhitungan Z-Score pada PT Bank Mandiri (Persero) Tbk, yang memiliki nilai Z-Score tertinggi adalah pada tahun 2018 yaitu sebesar 2,22. Kenaikan ZScore pada tahun 2018 ini jika diteliti disebabkan karena nilai dari varibel X1 yaitu modal kerja terhadap total aset memiliki rasio yang lebih tinggi yaitu 1,483760 dibandingkan tahun 2014 2017.

\section{SIMPULAN} hal yaitu:

Berdasarkan hasil pengolahan data dan pembahasan, maka dapat disimpulkan beberapa

a. Angka rata-rata nilai Z-Score pada PT Bank Mandiri (Persero) Tbk dengan skor 2,01.

b. Selama periode penelitian 2014 s.d. 2018 PT Bank Mandiri (Persero) Tbk mengalami ancaman kebangkrutan karena nilai $\mathrm{Z}$ score dibawah angka 2,6.

c. Tahun yang memiliki angka Z-Score paling kecil sehingga memiliki ancaman rawan kebangkrutan paling besar adalah tahun 2016 dengan nilai score 1,98.

d. Tahun yang memiliki angka Z-Score paling besar sehingga memiliki ancaman rawan kebangkrutan paling kecil adalah tahun 2018 nilai score 2,22.

SARAN

Berdasarkan simpulan di atas, maka saran yang kiranya dapat bermanfaat yaitu: 
a. Diharapkan pihak manajemen perusahaan lebih berhati-hati dalam hal manajemen aset perusahaan, jangan sampai modal kerja yang dihasilkan menjadi negatif. Maka perusahaan memperkecil hutang agar tidak terjadi hasil yang negatif. Kemudian biayabiaya operasional perusahaan juga diperhatikan penggunaannya agar lebih efisien, jangan sampai lebih besar dari pendapatan yang dihasilkan oleh perusahaan dan juga menambahkan ekuitas perusahaan.

b. Bagi peneliti selanjutnya diharapkan menggunakan lebih dari satu model analisis kebangkrutan, agar dapat dibandingkan antara model satu dengan yang lain.

\section{DAFTAR PUSTAKA}

Darsono dan Ashari, 2005. Pedoman Praktis Memahami Laporan Keuangan. Yogyakarta: CV Andi Offset

Endri. 2009. Prediksi Kebangkrutan Bank Untuk Menghadapi dan Mengelola Perubahan Lingkungan Bisnis: Analisis Model Altman Z- Score

Fakhrurozie. 2007. Analisis Pengaruh Kebangkrutan Bank Dengan Metode Altman Z-Score Terhadap Harga Saham Perusahaan Perbankan Di Bursa Efek. Jakarta

Hanafi, M. M. dan A. Halim. 2003. Analisis Laporan Keuangan. Yogyakarta: UPP STIM YKPN

Irmayanto, Juli. 2009. Bank dan Lembaga Keuangan. Jakarta: Universitas Trisakti

Ismail. 2011. Akuntansi Bank. Jakarta: Kencana Prenada Media Group

Lesmana, Rico. 2003. Pedoman Menilai Kinerja untuk Perusahaan Tbk, Yayasan, BUMN, BUMD, dan Organisasi Lainnya, Edisi Pertama. Jakarta: Elex Media Komputindo

Munawir, S. 2002. Analisis Laporan Keuangan. Yogyakarta: Liberty

Rudianto. 2013. Akuntansi Manajemen Informasi Untuk Pengambilan Keputusan Strategis. Jakarta: Erlangga

Sanusi, Anwar. 2011. Metodologi Penelitian Bisnis. Jakarta : Salemba Empat

Sugiyono. 2012.Metode Penelitian Bisnis. Bandung: Alfabeta

Toto, Prihadi. 2011. Analisis Laporan Keuangan Teori dan Aplikasi. Jakarta: PPM

Undang-undang Nomor 10 Tahun 1998 Tentang Perbankan

Undang-undang Nomor 4 Tahun 1998 Tentang Kepailitan

Wild, Jhon J. dan K.R Subramanyam. 2010. Analisis Laporan Keuangan. Edisi Sepuluh. Jakarta: Salemba Empat 